\title{
Microscopic Removal Function and the Relationship Between Slurry Particle Size Distribution and Workpiece Roughness During Pad Polishing
}

\author{
Tayyab Suratwala, $^{\dagger}$ Michael Feit, William Steele, Lana Wong, Nan Shen, Rebecca Dylla-Spears, \\ Richard Desjardin, Daniel Mason, Paul Geraghty, Philip Miller, and Salmaan Baxamusa
}

Lawrence Livermore National Laboratory, P.O. Box 808, Livermore, California 94551

Various ceria and colloidal silica polishing slurries were used to polish fused silica glass workpieces on a polyurethane pad. Characterization of the slurries' particle size distribution (PSD) (using both ensemble light scattering and single particle counting techniques) and of the polished workpiece surface (using atomic force microscopy) was performed. The results show the final workpiece surface roughness is quantitatively correlated with the logarithmic slope of the distribution function for the largest particles at the exponential tail end of the PSD. Using the measured PSD, fraction of pad area making contact, and mechanical properties of the workpiece, slurry, and pad as input parameters, an Ensemble Hertzian Gap (EHG) polishing model was formulated to estimate each particle's penetration, load, and contact zone. The model is based on multiple Hertzian contact of slurry particles at the workpiece-pad interface in which the effective interface gap is determined through an elastic load balance. Separately, ceria particle static contact and single pass sliding experiments were performed showing $\sim 1-\mathrm{nm}$ depth removal per pass (i.e., a plastic type removal). Also, nanoindentation measurements on fused silica were made to estimate the critical load at which plastic type removal starts to occur $\left(P_{\text {crit }} \sim 5 \times 10^{-5} \mathrm{~N}\right)$. Next the EHG model was extended to create simulated polished surfaces using the Monte Carlo method where each particle (with the calculated characteristics described above) slides and removes material from the silica surface in random directions. The polishing simulation utilized a constant depth removal mechanism (i.e., not scaling with particle size) of the elastic deformation zone cross section between the particle and silica surface, which was either $0.04 \mathrm{~nm}$ (for chemical removal) at low loads $\left(<\boldsymbol{P}_{\text {crit }}\right)$ or $1.0 \mathrm{~nm}$ (for plastic removal) at intermediate loads $\left(>P_{\text {crit }}\right)$. The simulated surfaces quantitatively compare well with the measured rms roughness, power spectra, surface texture, absolute thickness material removal rate, and load dependence of removal rate.

\section{Introduction}

$\mathrm{D}$ URING polishing (e.g., optical polishing of glass or chemical mechanical polishing (CMP) of $\mathrm{Si}$ wafers), complex mechanical and chemical interactions between the workpiece, polishing particles, solution, and lap occur. At the macroscopic level, material removal has been historically described by the widely used Preston equation $^{1,2}$ :

G. Pharr-contributing editor

Manuscript No. 33087. Received April 23, 2013; approved August 27, 2013.

${ }^{\dagger}$ Author to whom correspondence should be addressed. e-mail: suratwala1@1lnl.gov

$$
\frac{\mathrm{d} h}{\mathrm{~d} t}=k_{\mathrm{p}} \sigma_{\mathrm{o}} V_{\mathrm{r}}
$$

where $\mathrm{d} h / \mathrm{d} t$ is the average thickness removal rate, $\sigma_{\mathrm{o}}$ is the applied pressure, and $V_{\mathrm{r}}$ is the average relative velocity of the polishing particle relative to the workpiece. Many studies, particularly those in the CMP literature, have expanded Preston's model to include the effects of numerous phenomena including slurry fluid flow and hydrodynamic effects. ${ }^{3-5}$ More recently, we have explored the influence of a number of other macroscopic effects including pad viscoelastic behavior, friction effects, pad wear, workpiece deflection, workpiece-lap mismatch, residual stress effects, temperature, and material deposit on the pad on the overall shape of the workpiece. $^{6-8}$

At the microscopic and molecular level, which is represented by the macroscopic Preston constant $\left(k_{\mathrm{p}}\right)$ in Eq. (1), most approaches use the theory of Hertzian contact mechanics to describe the interactions (e.g., load and contact zone) between the slurry particles and the workpiece being polished. ${ }^{1,2}$ Luo and Dornfeld 9,10 introduced the concept of active and inactive particles, where only the larger, active particles load the workpiece and result in material removal. Dornfeld later extended the Hertzian contact model by accounting for adhesion forces and plastic deformation. $^{11}$ These approaches also account for the pad roughness (often referred to as pad microasperities), pad hardness, as well as the slurry's particle size distribution (PSD). The focus of these approaches has been largely on understanding and predicting the average material removal rate and how it scales with change in the slurry's PSD and pad properties. ${ }^{12,13}$

On the other hand, little effort has been devoted to quantitatively understanding and predicting the surface roughness and texture of the workpiece as a function of the PSD and pad properties. Some studies have examined the effect of the slurry's PSD on scratches either by spiking the slurry with larger particles ${ }^{14-16}$ or by changing the overall PSD. ${ }^{17,18}$ However, these studies focused on a regime where the load particle exceeded the initiation load for fracture (typically $>0.1 \mathrm{~N}$ ) leading to brittle fracture.

In this study, the relationship of the slurry's PSD with the resulting rms surface roughness, power spectra, and texture of the polished workpiece is examined. The results of this study illustrate the importance of the relatively few larger particles in the slurry and the impact of the shape of the tail of the distribution to the surface roughness resulting in greater insight as to the nature of the removal mechanism during polishing. These results provide guidance into the design of new, cost effective polishing processes to provide low roughness surfaces, which is useful in high end optic applications demanding low optical scatter (e.g., high fluence laser optics, short wavelength optics, and telescope optics). 


\section{Experimental Procedure}

\section{(1) Particle Size Distribution}

Five different commercial polishing slurries were used in this study: S1) ACuPLANE ${ }^{\mathrm{TM}} 5120$ colloidal silica (Dow Chemical, Midland, MI); S2) Stabilized Hastilite PO cerium oxide; S3) Unstabilized Hastilite PO cerium oxide (Universal Photonics, Hicksville, NY); S4) Ultra-Sol ${ }^{\circledR} 3005$ cerium oxide (Eminess Technologies); and S5) Ultra-Sol ${ }^{\circledR} 3030$ cerium oxide (Eminess Technologies, Scottsdale, AZ). Note that Stabilized Hastilite PO is the same as Unstabilized Hastilite PO except that it has been chemically modified to improve the tail end of the PSD (details are described elsewhere ${ }^{19}$ ). The PSDs of the polishing slurries were measured using both static light scattering (Saturn Digisizer; Micromeritics, Norcross, GA) and single particle optical sensing (Accusizer Autodilutor AD, Particle Sizing Systems, Inc., Port Richey, FL). The static light scattering technique simultaneously measures the scatter of an ensemble of particles and uses Mie scattering theory to determine the best fit PSD. This technique is best suited for small particles (down to $40 \mathrm{~nm}$ ) and for obtaining the general shape of the PSD. In contrast, single particle optical sensing measures the scatter of one particle at a time. This technique provides greater sensitivity to the largest particles at the tail end of the distribution. Using the Accusizer, only particles above $500 \mathrm{~nm}$ are measured. Samples were measured in triplicate; the error bar in the measured data is noted as the variation in the three measurements.

\section{(2) Polishing}

Fused silica workpieces $(100 \mathrm{~mm}$ diameter $\times 10 \mathrm{~mm}$ thick or $25 \mathrm{~mm} \times 25 \mathrm{~mm} \times 5 \mathrm{~mm}$ thick square; Corning 7980, Corning, NY) were polished using the convergent polishing $\operatorname{method}^{7}$ for $8 \mathrm{~h}(0.3 \mathrm{psi}$ applied pressure, $20 \mathrm{rpm}$ optic and lap rotation rates, $0.6 \mathrm{~mL} / \mathrm{min}$ slurry feed rate (single pass)). A new polyurethane polishing pad (IC1000; Rohm \& Haas, Phoenix, AZ) was used for each change in polishing slurry. Material removal rates were determined gravimetrically. Because the slurry is only used on a single pass through the polisher, changes to the slurries' PSD with recirculation are not considered in this study.

\section{(3) Single Ceria Particle Static and Sliding Contact Measurements}

Square fused silica workpieces $(25 \mathrm{~mm} \times 25 \mathrm{~mm} \times 5 \mathrm{~mm})$ were first polished using the ACuPLANE ${ }^{\mathrm{TM}}$ polishing slurry using the method described above to obtain low rms roughness. These low roughness samples were then placed on a polishing pad, which was precharged with Stabilized Hastilite slurry (Baume 9 diluted $400 \times$ in water), and either statically loaded $(0.3 \mathrm{psi})$ or slid $(20 \mathrm{~cm} / \mathrm{s})$ in a single pass over the pad. Note the concentration of slurry was $\sim 400 \times$ lower than that used for the polishing experiments described above to resolve the single ceria particle interactions with the fused silica surface. The sample was then aggressively rinsed with deionized water for $30 \mathrm{~min}$ and etched in $\mathrm{HNO}_{3}: \mathrm{H}_{2} \mathrm{O}_{2}$ for $30 \mathrm{~min}$ to remove any residual ceria particles on the surface of the sample. In some of the samples, the slurry was allowed to dry before rinsing and treating with $\mathrm{HNO}_{3}: \mathrm{H}_{2} \mathrm{O}_{2}$.

\section{(4) Nanoindentation}

On the square fused silica workpieces $(25 \mathrm{~mm} \times 25 \mathrm{~mm} \times$ $5 \mathrm{~mm}$ polished using the ACuPLANE ${ }^{\mathrm{TM}}$ polishing slurry), nanoindentation was performed using a Berkovitch B1951 tip at a loading/unloading rate of $30 \mathrm{~nm} / \mathrm{s}$ to various maximum loads ranging from $10^{-5}$ to $0.1 \mathrm{~N}$. The displacement at maximum load (corresponding to a combined elastic and plastic deformation) and after unloading (corresponding to permanent plastic deformation) were measured. Depths down to $\sim 3 \mathrm{~nm}$ could be resolved.

\section{(5) Surface Roughness}

The surface morphology and roughness of each of the polishing samples were characterized using atomic force microscopy (Digital Instrument Dimension 3100, Billerica, MA). High aspect ratio silicon tips (Veeco OTESPAW, Plainview, NY) were used to ensure the accuracy of the AFM results and to minimize any tip convolution of the shapes measured. Instrument resolution was $\sim 10 \mathrm{~nm}$ and $\sim 1 \mathrm{~nm}$ laterally for the $50 \mu \mathrm{m} \times 50 \mu \mathrm{m}$ and $5 \mu \mathrm{m} \times 5 \mu \mathrm{m}$ scans, respectively. Measurements on each sample were typically repeated in triplicate.

\section{(6) Areal Pad Contact}

Using a simple graphite embossing technique, the fraction of the pad area making contact with the workpiece at various applied loads was determined. First, a graphite pencil was used to mark a $25 \mathrm{~mm} \times 25 \mathrm{~mm}$ area on a piece of paper which was then placed face up on a flat surface. Next, a polyurethane pad adhered to a weight was placed onto the graphite surface with the pad side facing down for a few seconds. Note a slight lateral motion likely occurs resulting in some friction force at the interface. Using reflectance optical microscopy, the areal fraction on the pad surface observed with graphite deposits was measured (12 images at a $2.37 \mathrm{~mm} \times 1.87 \mathrm{~mm}$ field of view). The process was repeated at different applied pressures on the pad.

\section{Results}

\section{(1) Particle Size Distribution}

Figure 1(a) shows the fractional number PSD [f(r)] of the ceria slurries used in the study as measured using static light scattering. The Stabilized and Unstabilized Hastilite (S2 and S3) slurries have very similar distributions with a mean size of $\sim 100 \mathrm{~nm}$. Likewise, Ultra-Sol 3005 and Ultra-Sol 3030 (S4 and S5) also have very similar distributions with a mean size of $50 \mathrm{~nm}$. However, the tail ends of the slurry PSDs (which by definition involve only a small fraction of the total number of particles) are found to be very different. This is illustrated in Fig. 1(b) which shows the fractional number PSD $[f(r)]$ of the slurries as measured by single particle optical sensing on a semilog plot. The tails of the distributions can be described by a single exponential size dependence [as shown by the lines in Fig. 1(b)] in the form:

$$
f(r)=A e^{\frac{-2 r}{d_{\mathrm{PSD}}}}
$$

where $r$ is the particle radius, $A$ is a preexponential constant, and $d_{\mathrm{PSD}}$ is the inverse exponential slope in the PSD. Normalization of $f(r)$ is with respect to diameter, i.e., the integral of $f(r)$ over all values of $r$ equals $1 / 2$.

\section{(2) Surface Roughness and Power Spectra}

Figure 2 shows the surface morphology (as measured by AFM) of the fused silica surfaces after polishing with the various slurries S1-S5. All of the surfaces are plotted on the same linear vertical scale from $-4.0 \mathrm{~nm}$ to $4.0 \mathrm{~nm}$. The roughness varied significantly, increasing from $\mathrm{S} 1-\mathrm{S} 5$. We find a quantitative correlation between the exponential inverse slope of the volumetric PSD $\left(d_{\mathrm{PSD}}\right)$ and the rms roughness $(\delta)$ (as shown in Fig. 3), which follows the form:

$$
d_{\mathrm{PSD}}=d_{o} e^{\frac{-\delta}{\delta_{o}}}
$$

where $d_{o}$ and $\delta_{o}$ are constants with the values of $0.008 \mu \mathrm{m}$ and $0.2 \mathrm{~nm}$, respectively. 


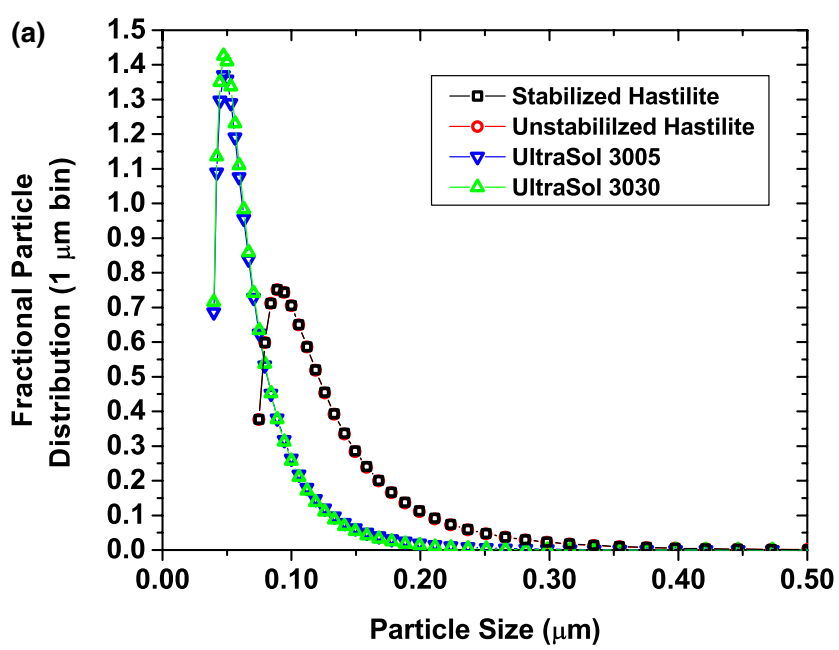

(b)

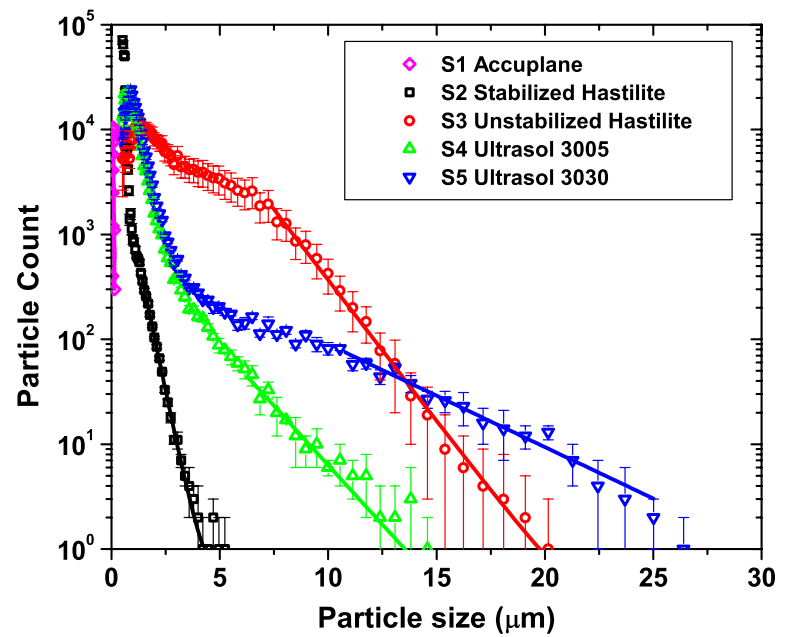

Fig. 1. (a) Measured particle size distribution (PSD) on a linear scale using static light scattering for various ceria polishing slurries; (b) Measured PSD for the same ceria slurries on a log scale using single particle optical sensing (Accusizer).

\section{(3) Pad-Workpiece Interface Characteristics}

Figure 4 summarizes the pad areal contact fraction $\left(f_{\mathrm{A}}\right)$ results as a function of applied pressure. A linear increase in the areal contact fraction was observed with applied pressure. Also, the absolute contact area was small $\left(f_{\mathrm{A}}=5 \times 10^{-4}\right.$ at $\left.0.3 \mathrm{psi}\right)$ indicating that very little of the pad cross-sectional area is making contact with the workpiece during polishing.

\section{(4) Single Ceria Particle Removal Function (Plastic and Molecular Removal)}

The AFM images $(2 \mu \mathrm{m} \times 2 \mu \mathrm{m})$ of the fused silica surface after static ceria particle loading [Fig. 5(a)] and after single pass ceria particle sliding [Fig. 5(b)] using Stabilized Hastilite slurry (S2) illustrate the interactions of single ceria particles with the silica surface. The plot on the right of each surface image is a height lineout through the center of the image. Note that before the treatment, the fused silica substrate was polished with the ACuPLANE ${ }^{\mathrm{TM}}$ slurry (S1) which provided very smooth surfaces with an rms surface roughness of $0.23 \mathrm{~nm}$ [see Fig. 2(a)]; hence it is reasonable to conclude that the features observed after ceria particle contact are due to the ceria-silica interactions. In the static ceria particle loading case, pits, typically 10-50 nm wide and $\sim 1 \mathrm{~nm}$ deep, were observed. The lateral size of observed pits is indicative of the contact zone size between the ceria particle and the fused silica surface. In the sliding ceria particle case, linear tracks were observed in the direction of the ceria sliding with a typical depth of $\sim 1 \mathrm{~nm}$. These results define some important aspects of the material removal function of a single ceria particle during polishing. The depth of removal of $\sim 1 \mathrm{~nm}$ is $\sim 6 \mathrm{Si}-\mathrm{O}-\mathrm{Si}$ units, suggesting that removal or modification can occur over depths beyond a single molecular level, through either plastic flow deformation or densification.

\section{(5) Nanoindentation}

Figure 6 summarizes the nanoindentation results versus applied load. The indenter displacement into the fused silica workpiece at maximum load describes the combined elastic, plastic, and densification deformation, whereas the indenter displacement after unload describes plastic and densification deformation only. Our results are consistent with data collected in the higher load range from Shorey et. al., ${ }^{20}$ whose data is also plotted in Fig. 6. The displacement at maximum load follows a power law dependence; the displacement at unload also follows a power law dependence except at very low loads. The smallest permanent deformation displacement measureable was $\sim 5 \mathrm{~nm}$ at an applied load of $10^{-4} \mathrm{~N}$. Extrapolating the displacement at unload curve to a displacement $\sim 1 \mathrm{~nm}$ (as discussed in Section III(4)) suggests that the load to achieve minimum permanent deformation is $\sim 5 \times 10^{-5} \mathrm{~N}$. At loads much lower than this, elastic deformation with no permanent deformation is expected to occur. In the discussion section below, this load $\left(P_{\text {crit }}=5 \times\right.$ $\left.10^{-5} \mathrm{~N}\right)$ is proposed as the approximate transition between chemical type material removal and plastic type material removal during polishing.

\section{Discussion}

\section{(1) Relationship Between the Tail End of the PSD and the Resulting Surface Roughness}

As discussed in Section III(2), there is a quantitative correlation between the tail end of the PSD of the polishing slurry and the roughness of the resulting polished fused silica glass surface. This implies that the largest particles (either larger single particles or agglomerates) dominate in modifying the morphology of the surface, whereas average-sized particles (and hence the majority of the particles in the slurry) have little or no influence on removal and the resulting surface roughness. A similar set of concepts were proposed when investigating overall material removal rate during CMP wafer polishing ${ }^{9,10}$ and also with grinding processes on glass. ${ }^{14}$

In the following discussion, we propose a model that quantitatively correlates the PSD to multiple aspects of the polished surface (e.g., texture, rms roughness, and power spectra). An outline of the proposed conceptual connection between the two is illustrated in Fig. 7. Using the multiple Hertzian contact concept, which we call the Ensemble Hertzian Gap (EHG) model, contact characteristics (load, contact zone, and elastic penetration) for each particle at the interface are determined using an elastic load balance and calculating the gap at the interface (Section IV(2)). Next, proposed material removal mechanisms of single ceria particles at varying loads are described (Section IV(3)). Then, polishing simulations at the microscopic scale are conducted using the Monte Carlo method and the results are compared with the experimental data (Section IV $(4)$ ). Finally, in Section IV(5), comparisons between the combined EHG model and polishing simulations with the observed macroscopic material removal rates are discussed.

\section{(2) Ensemble Hertzian Gap (EHG) Model}

Consider an ensemble of slurry particles (with modulus $\mathrm{E}_{3}$ and Poisson's ratio $v_{3}$ ) having a PSD $[f(r)]$ elastically compressed with a total load $\left(P_{\mathrm{a}}\right)$ between a workpiece (of radius $r_{\mathrm{o}}$, modulus $\mathrm{E}_{1}$, and Poisson's ratio $v_{1}$ ) and a pad (with modulus $\mathrm{E}_{2}$ and Poisson's ratio $v_{2}$ ) as shown in the sche- 


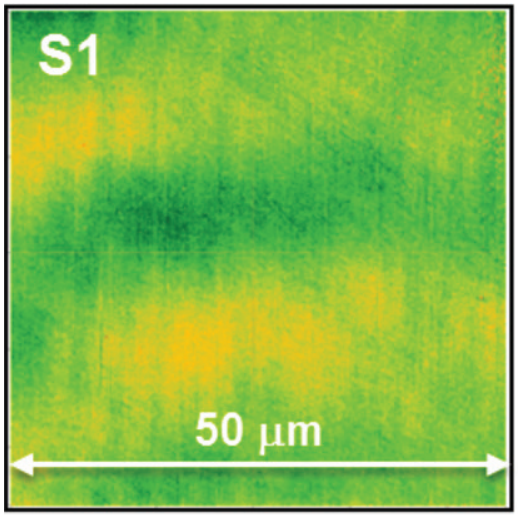

(a)

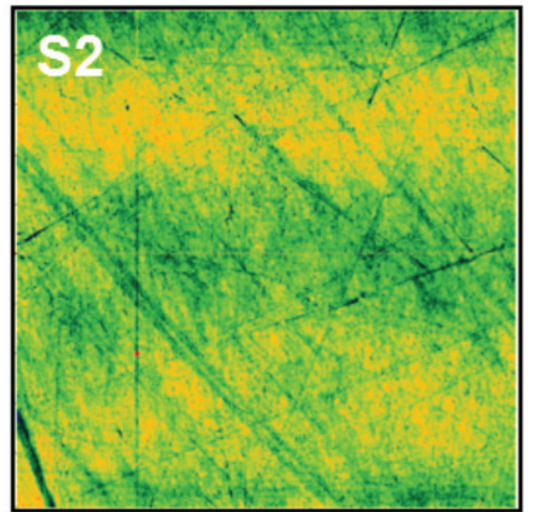

(b)

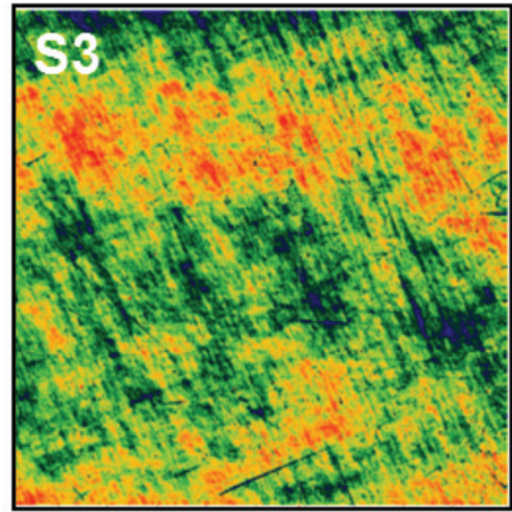

(c)

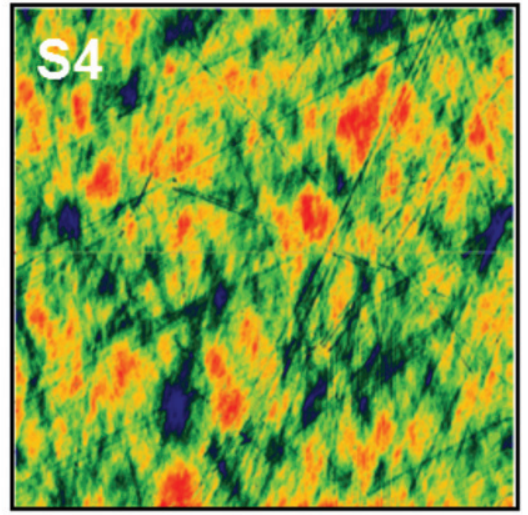

(d)
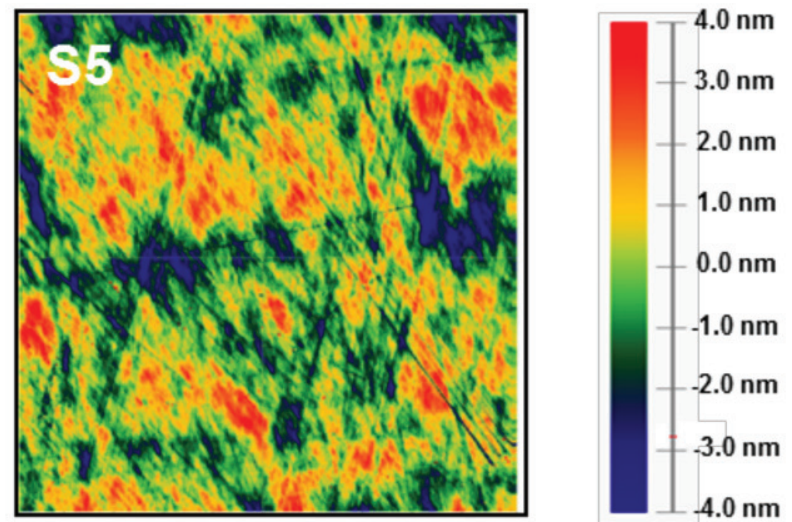

(e)

Fig. 2. AFM images $(50 \mu \mathrm{m} \times 50 \mu \mathrm{m})$ of the fused silica surfaces after polishing with various slurries (S1-S5).

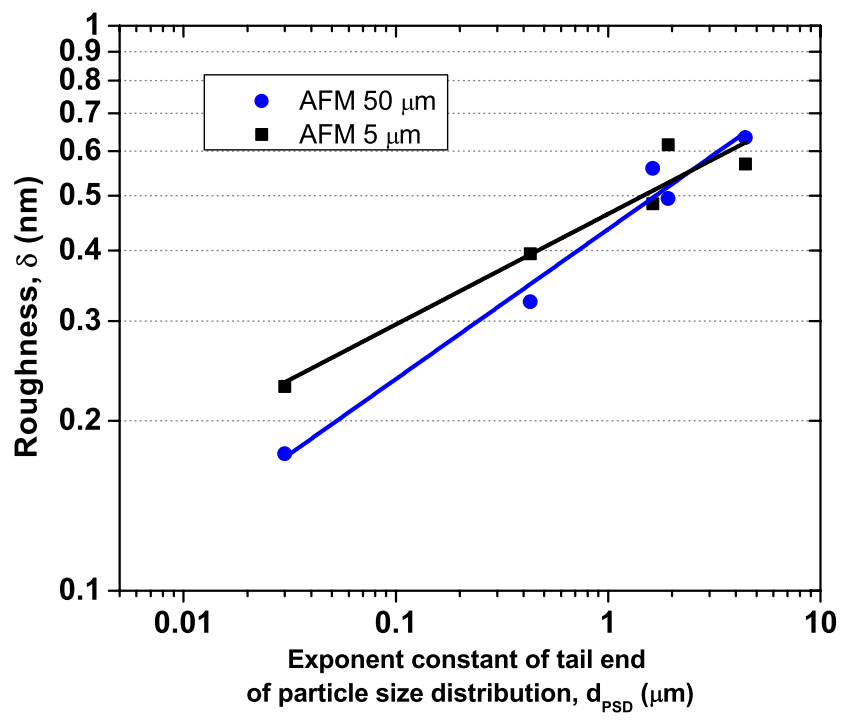

Fig. 3. Roughness $(\delta)$ of fused silica surface over various spatial scale lengths as a function of the exponential constant $\left(d_{\mathrm{PSD}}\right)$ of the tail end of the slurry's PSD.

matic in Fig. 8. The load is carried by a fraction of the total number of particles, the active particles, which are determined by the equilibrium gap $(g)$ at the interface as found from a simple elastic load balance. In other words, particles smaller than the gap (called inactive particles) are not loaded and do not participate in polishing.

Some key assumptions have been made to simplify the analysis. First, all the particles are assumed to be spherical.

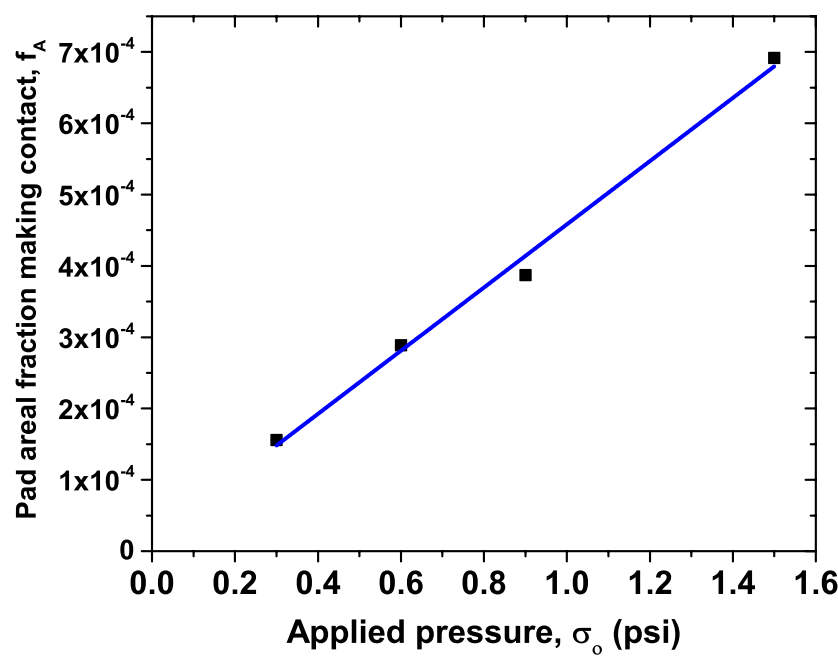

Fig. 4. Measured fraction of pad area making contact $\left(f_{\mathrm{A}}\right)$ with workpiece as a function of applied pressure $\left(\sigma_{o}\right)$.

Second, hydrodynamic fluid forces are considered largely negligible here. Third, particles are distributed at the workpiece-lap interface as a single layer of particles. In reality, the particles likely stack, which implies some smaller particles are loaded; whereas in a stack, which allows for decreasing the load on larger particles. As accounting for stacking particles would require a more complex model of interacting, stacking particles for which a formalism has not been established, a simpler, single layer approach is used in this study. However, even with particle stacking, the expectation is that 

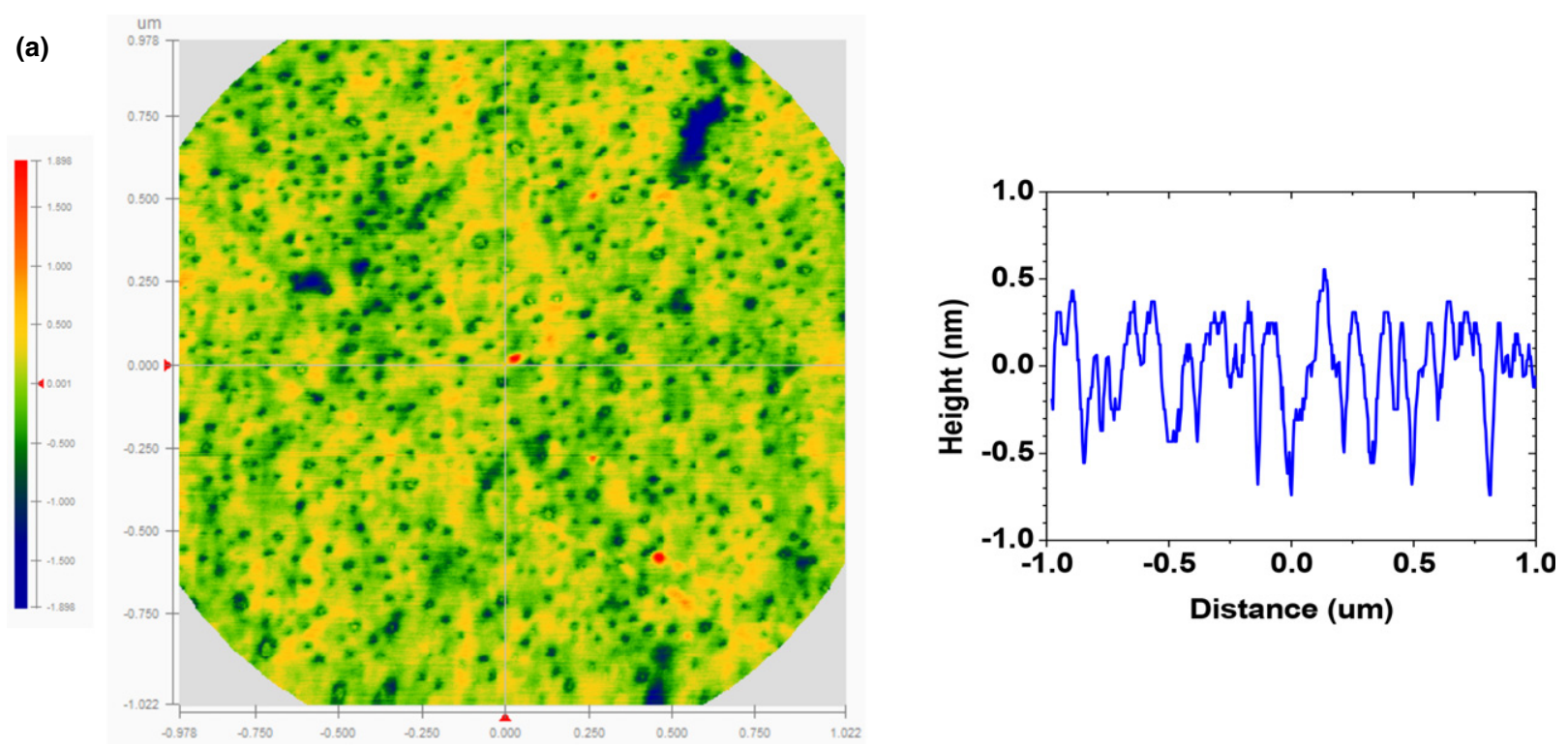

(b)
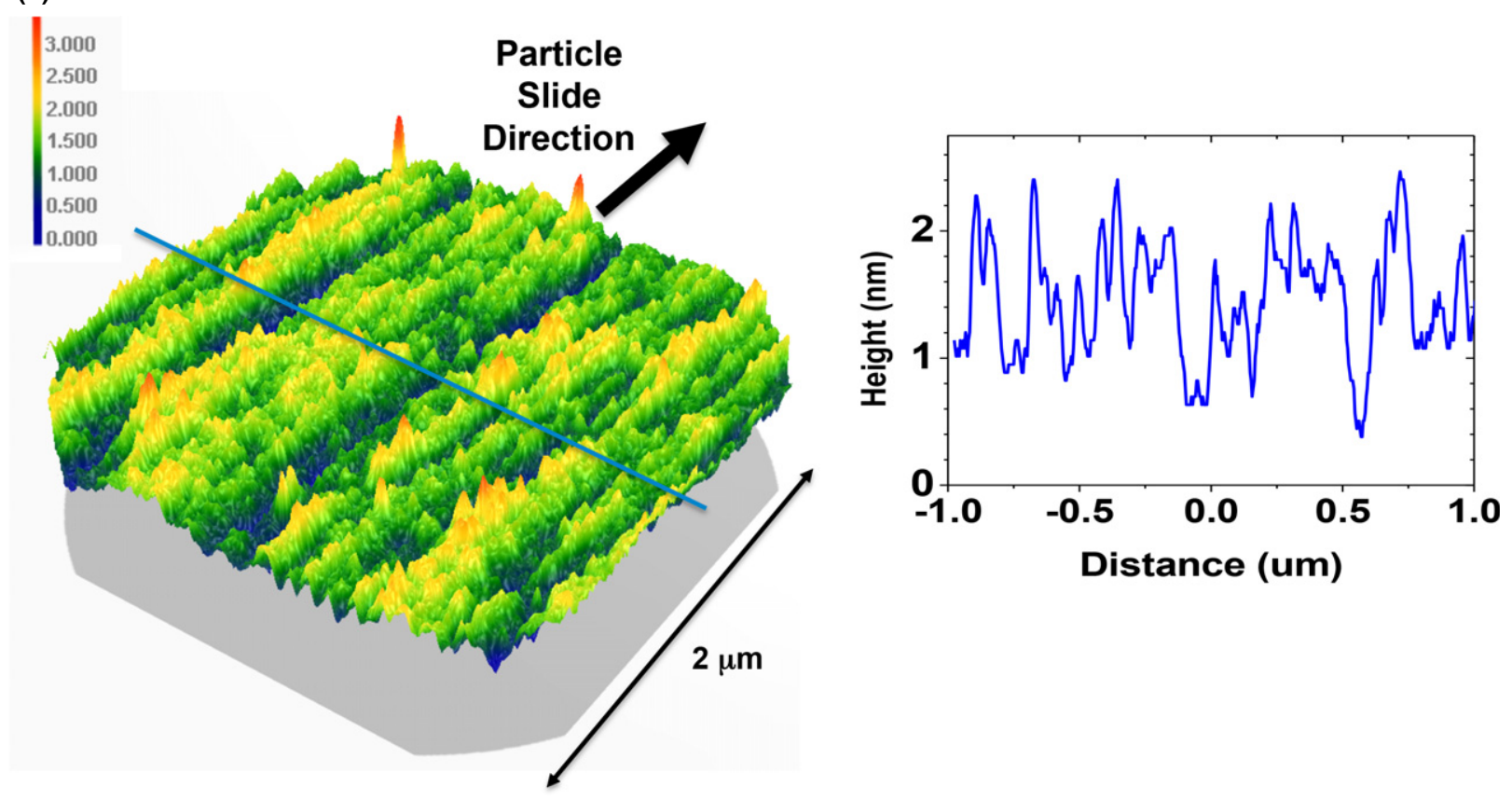

Fig. 5. (a) (Left) AFM image $(2 \mu \mathrm{m} \times 2 \mu \mathrm{m})$ of fused silica surface after ceria slurry was statically loaded under pad (at 0.3 psi using stabilized hastilite), allowed to dry, and then removed using nitric-peroxide etch. (Right) Lineout of surface; (b) (Left) AFM image ( $2 \mu \mathrm{m} \times 2 \mu \mathrm{m})$ of fused silica surface after single pass ceria slurry slide $(10 \mathrm{~cm} / \mathrm{s}$ at $0.3 \mathrm{psi}$ using stabilized hastilite). (Right) Lineout of surface perpendicular to particle sliding direction.

the larger particles will still bear higher loads relative to the smaller ones, which is captured in the proposed single particle layer model. Fourth, the larger particles, which are often agglomerated particles, are assumed to have the same mechanical properties and behavior as single solid particles of the same size. Note in relation to the last assumption there are previous reports of the agglomerated particle breaking down with slurry recirculation changing the PSD. ${ }^{21}$ In this study, slurry was used in single pass (i.e., no recirculation), hence the initially measured PSD is appropriate. Finally, we assume that the formalism for determining the load per particle uses only elastic contact mechanics, absent plastic deformation or densification, which would require a more complex model. However, we do not expect this assumption to significantly change calculated values for the load/particle or the contact zone.

It is convenient to describe the composite moduli of contact for this 3-body system as follows ${ }^{22}$ :

$$
\begin{aligned}
& E_{\mathrm{eff}}=\frac{E_{13} E_{23}}{\left(E_{13}^{2 / 3}+E_{23}^{2 / 3}\right)^{3 / 2}} \\
& E_{13}=\left(\frac{\left(1-v_{1}\right)^{2}}{E_{1}}+\frac{\left(1-v_{3}\right)^{2}}{E_{3}}\right)^{-1} \\
& \mathrm{E}_{23}=\left(\frac{\left(1-v_{2}\right)^{2}}{\mathrm{E}_{2}}+\frac{\left(1-v_{3}\right)^{2}}{\mathrm{E}_{3}}\right)^{-1}
\end{aligned}
$$

where $E_{\text {eff }}$ is the effective modulus of the 3-body system, $E_{13}$ is the composite modulus at the workpiece-slurry particle interface, and $E_{23}$ is the composite modulus at the pad-slurry particle interface. From Hertzian contact mechanics, ${ }^{23}$ the 


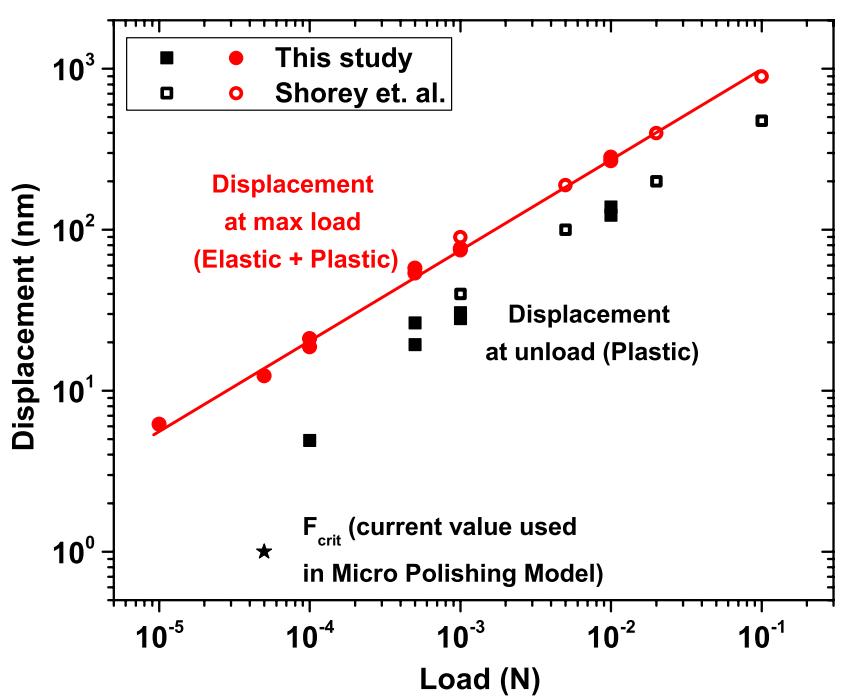

Fig. 6. Measured displacement (both at maximum load representing elastic and plastic deformation and at unload representing permanent plastic deformation) on fused silica surface after nanoindentation at various loads. The open data points are data from Shorey ${ }^{21}$ and the solid data points are from this study. $P_{\text {crit }}$ value used in micropolishing model is noted by a star in the plot.

load on each particle of radius $(r)$ is then given by the following equation:

$$
P(r, g)=\frac{4}{3} \mathrm{E}_{\mathrm{eff}} \sqrt{r(2 r-g)^{3}}
$$

Once the single value equilibrium gap $(g)$ is determined, the load on each particle is known. To determine $g$, a load balance is used for the whole system given by the following equation:

$$
\mathbf{P}_{A}=f_{A} \mathrm{~N}_{t} 2 \pi r_{o}^{2} \int_{\frac{g}{2}}^{\infty} f(r) P(r, g) \mathrm{d} r
$$

where $P_{\mathrm{A}}$ is the total load, $f_{\mathrm{A}}$ is the fraction of the pad area making contact with the workpiece and $N_{\mathrm{t}}$ is the areal number density of particles present at the interface. Then, it is straightforward to determine the depth of penetration and the contact zone for each slurry particle as well, which are given by the following equations:

$$
\begin{aligned}
& d_{t}(r, g)=\left(\frac{3 P(r, g)}{4 E_{\mathrm{eff}} \sqrt{r}}\right)^{2 / 3} \\
& d_{13}(r, g)=d_{t}(r, g)\left(\frac{E_{\mathrm{eff}}}{E_{13}}\right)^{2 / 3} \\
& d_{23}(r, g)=d_{t}(r, g)\left(\frac{E_{\mathrm{eff}}}{E_{23}}\right)^{2 / 3}
\end{aligned}
$$

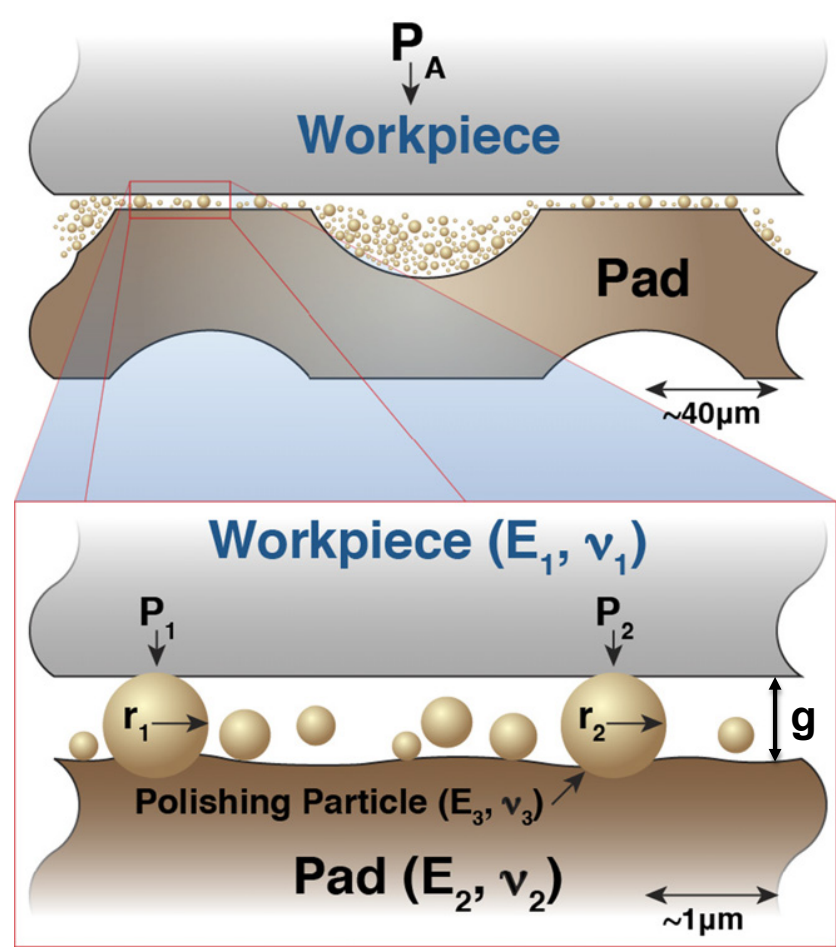

Fig. 8. Schematic illustration of the ensemble hertzian gap model for a single layer of slurry particles at the interface during polishing.

$$
a_{13}(r, g)=\sqrt{r d_{13}(r, g)} \quad a_{23}(r, g)=\sqrt{r d_{23}(r, g)}
$$

where $d_{\mathrm{t}}$ is the total depth of penetration of the particle into the workpiece and lap, $d_{13}$ and $a_{13}$ are the depth of penetration and contact radius into the workpiece, and $d_{23}$ and $a_{23}$ are the depth of penetration and contact radius into the pad.

Using the measured PSD $[f(r)]$ (see Section III(1)), the measured fraction of pad area making contact $\left(f_{\mathrm{A}}\right)$ (see Section III(3)), and known material mechanical properties (Table I), the results of the calculation of the EHG model are described for two slurries (Stabilized (S2) and Unstabilized (S3) Hastilite PO) in Table II and Fig. 9. The effective gaps at the interface were determined as 0.07 and $0.43 \mu \mathrm{m}$, respectively. The average contact size calculated for Stabilized Hastilite (S2) (see Table II) is consistent with the size of the contact zone measured with the static ceria contact experiment [Fig. 5(a)]. Figure 9 compares the calculated fraction of the total load carried by each particle size and the load/ particle as a function of particle size for the same two slurries. The majority of the total load $\left(P_{\mathrm{a}}\right)$ is still carried by the large number of smaller active particles; however, the load on individual particles is the largest on the larger particles in the PSD of the slurry. For Stabilized Hastilite (S2), the largest active particles are $\sim 0.9 \mu \mathrm{m}$ each with a load of $5 \times 10^{-4} \mathrm{~N}$; for Unstabilized Hastilite (S4), the largest active particles are much larger $(\sim 10 \mu \mathrm{m})$ each with a load of

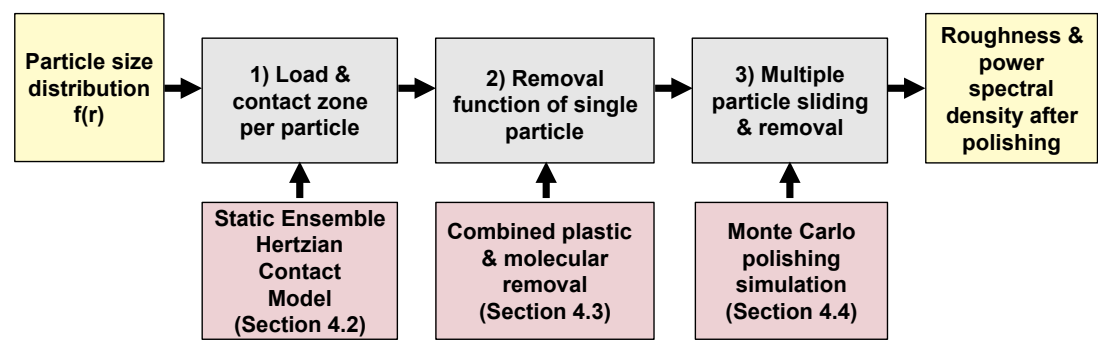

Fig. 7. Schematic illustrating proposed connection between volumetric PSD and polished workpiece surface roughness. 
Table I. Input Parameters Used in Ensemble Hertzian Contact Model and Monte Carlo Polishing Simulations

\begin{tabular}{|c|c|c|c|}
\hline Parameter & Variable & Source & Value \\
\hline $\begin{array}{l}\text { Slurry particle size } \\
\text { distribution }\end{array}$ & $f(\mathrm{r})$ & Measured & $\begin{array}{l}\text { See Figs. (1) } \\
\text { and (2) }\end{array}$ \\
\hline $\begin{array}{l}\text { Modulus and Poisson's } \\
\text { ratio of workpiece }\end{array}$ & $E_{1}, v_{1}$ & Measured & $73 \mathrm{GPa} ; 0.17$ \\
\hline $\begin{array}{l}\text { Modulus and Poisson's } \\
\text { ratio of pad }\end{array}$ & $E_{2}, v_{2}$ & Measured & $314 \mathrm{MPa} ; 0.22$ \\
\hline $\begin{array}{l}\text { Modulus and Poisson's } \\
\text { ratio of ceria }\end{array}$ & $E_{3}, v_{3}$ & Measured & $190 \mathrm{GPa} ; 0.20$ \\
\hline Relative velocity & $V_{\mathrm{r}}$ & Measured & $19.8 \mathrm{~cm} / \mathrm{s}$ \\
\hline $\begin{array}{l}\text { Fraction of pad area } \\
\text { making contact }\end{array}$ & $f_{\mathrm{A}}$ & Measured & $1.5 \times 10^{-4}$ \\
\hline $\begin{array}{l}\text { Areal stacking density } \\
\text { of particles }\end{array}$ & $N_{\mathrm{t}}$ & Best fit & $30 \mu \mathrm{m}^{-2}$ \\
\hline Plastic removal depth & $d_{\mathrm{p}}$ & Measured & $1.0 \mathrm{~nm}$ \\
\hline $\begin{array}{l}\text { Molecular removal } \\
\text { depth }\end{array}$ & $d_{\mathrm{m}}$ & Best fit & $0.04 \mathrm{~nm}$ \\
\hline $\begin{array}{l}\text { Critical load need for } \\
\text { plastic removal }\end{array}$ & $P_{\text {crit }}$ & Measured & $5 \times 10^{-5} \mathrm{~N}$ \\
\hline
\end{tabular}

Table II. Comparison of Slurry Contact Parameters Calculated from the Ensemble Hertzian Contact Model and Using the Proposed Combined Plastic and Chemical Removal During Polishing. Also, shown at bottom is the calculated Average Material Removal Rate Determined Using Eq (9).

\begin{tabular}{lllc}
\hline Parameter & Variable & $\begin{array}{c}\text { Stabilized } \\
\text { hastilite }\end{array}$ & $\begin{array}{c}\text { Unstabilized } \\
\text { hastilite }\end{array}$ \\
\hline $\begin{array}{l}\text { (1) Fraction of active } \\
\text { particles }\end{array}$ & $f_{\mathrm{r}}$ & 0.224 & 0.0005 \\
$\begin{array}{l}\text { (2) Fraction of active } \\
\text { particles with plastic } \\
\text { removal }\end{array}$ & $f_{\mathrm{p}}$ & 0.001 & 0.650 \\
$\begin{array}{l}\text { (3) Fraction of active } \\
\text { particles with chemical } \\
\text { removal }\end{array}$ & $f_{\mathrm{m}}$ & 0.999 & 0.350 \\
$\begin{array}{l}\text { (4) Average contact } \\
\text { radius for plastically } \\
\text { loaded particles }\end{array}$ & $a_{\mathrm{p}}$ & $55 \mathrm{~nm}$ & $217 \mathrm{~nm}$ \\
$\begin{array}{l}\text { (5) Average contact } \\
\text { radius for molecularly } \\
\text { loaded particles }\end{array}$ & $a_{\mathrm{m}}$ & $9.5 \mathrm{~nm}$ & $34 \mathrm{~nm}$ \\
$\begin{array}{l}\text { Calculated removal } \\
\text { rate [Eq. (9)] }\end{array}$ & $\mathrm{d} h / \mathrm{d} t$ & $0.54 \mu \mathrm{m} / \mathrm{h}$ & $0.77 \mu \mathrm{m} / \mathrm{h}$ \\
\hline
\end{tabular}

$8 \times 10^{-2} \mathrm{~N}$. This is $10 \times$ greater in particle size and $\sim 100 \times$ in load for the Unstabilized Hastilite, even though they have the same average particle size of $0.10 \mu \mathrm{m}$.

\section{(3) Material Removal Mechanism}

Material removal from the glass surface has been proposed to occur by three basic mechanisms: (1) fracturing, (2) plastic flow, and (3) chemical reaction. During grinding where material removal rates are high, the dominant material removal mechanism is by fracturing ${ }^{24}$; here, the load/particle on the workpiece is very high $P_{f}>0.1 \mathrm{~N}$ (which is the fracture initiation load for indentation). ${ }^{23}$

At the other extreme (i.e., very low nonzero load/particle), the material removal mechanism on glass is proposed to be chemical. The most widely accepted chemical mechanism for ceria particles on silica glass is that proposed by Cook, ${ }^{25}$ who proposed that chemical material removal occurs through condensation and hydrolysis reactions given by the following equation:

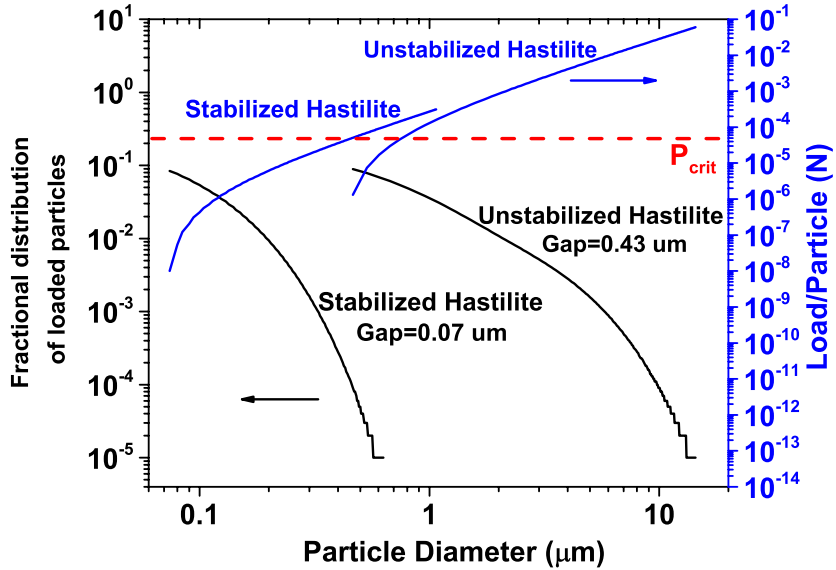

Fig. 9. Calculated parameters (fractional distribution of loaded particles and load/particle $(P)$ as function of the particle size) using ensemble hertzian gap model for stabilized hastilite (S2) and unstabilized hastilite (S3). Above the dashed line marking $P_{\text {crit }}$, plastic removal occurs and below the dashed line, chemical removal occurs.

$$
=\mathrm{Ce}-\mathrm{OH}+\mathrm{HO}-\mathrm{Si} \equiv \rightarrow=\mathrm{Ce}-\mathrm{O}-\mathrm{Si} \equiv+\mathrm{H}_{2} \mathrm{O}
$$

where the surface of the cerium oxide particle is cerium hydroxide, which condenses with the glass surface (silanol surface) to form a $\mathrm{Ce}-\mathrm{O}-\mathrm{Si}$ bond. The bond strength of this new oxide is greater than the strength of the $\mathrm{Si}-\mathrm{O}-\mathrm{Si}$ bond (i.e., the glass). It is well-known that parameters such as $\mathrm{pH}$, isoelectric point, water interactions, slurry concentration, slurry PSD, and other chemical parameters can influence the removal rate. ${ }^{25}$ In other words, polishing is thought to occur as ceria particles repeatedly tear away the silica network at the molecular scale (i.e., implying single pass removal at the Angstrom scale).

In the intermediate load regime, some studies have proposed material removal by plastic flow, sometimes called ductile grinding. ${ }^{26,27}$ On the basis of the single ceria slide experiments described in Section $\operatorname{III}(5)$, we see evidence of removal at the nm level, suggestive of plastic flow or densification at loads per particle of $P_{\text {crit }}>5 \times 10^{-5} \mathrm{~N}$. In the following model, we propose that both chemical $\left(P<P_{\text {crit }}\right)$ and plastic $\left(P_{\text {crit }}<P<P_{f}\right)$ removal occur during polishing, and the load/particle determines which removal mechanism is dominant. As shown in Fig. 9 from the EHG model, Unstabilized Hastilite (S3) has a larger fraction of active particles with a load/particle greater than $P_{\text {crit }}$ implying material removal dominated by plastic flow. Similarly, Stabilized Hastilite (S2) has a larger fraction of active particles less than $P_{\text {crit }}$ implying material removal dominated by the chemical mechanism.

Other important aspects of the material removal function of a single sliding slurry particle are the track width and its cross-sectional shape. In this model, we propose the removal width is equivalent to the width of the Hertizian contact zone $\left(2 a_{13}\right)$. So as the particle size increases, the width of the single particle removal zone increases. The cross-sectional shape of the removal is not as clear; hence two different types of cross-sectional shape removal functions were evaluated in this study. The first one assumes the amount of material removed is proportional to the cross-sectional area of the elastic trench created by the particle (where $2 a_{13}$ is the contact zone and $d_{13}$ the elastic penetration depth) (See Fig. 10 top right). This removal mechanism is referred to as the "constant area fraction" mechanism. There is a theoretical attraction to this assumption because Hertzian mechanics states the cross-sectional area is proportional to the load on 


\section{Constant area fraction mechanism}

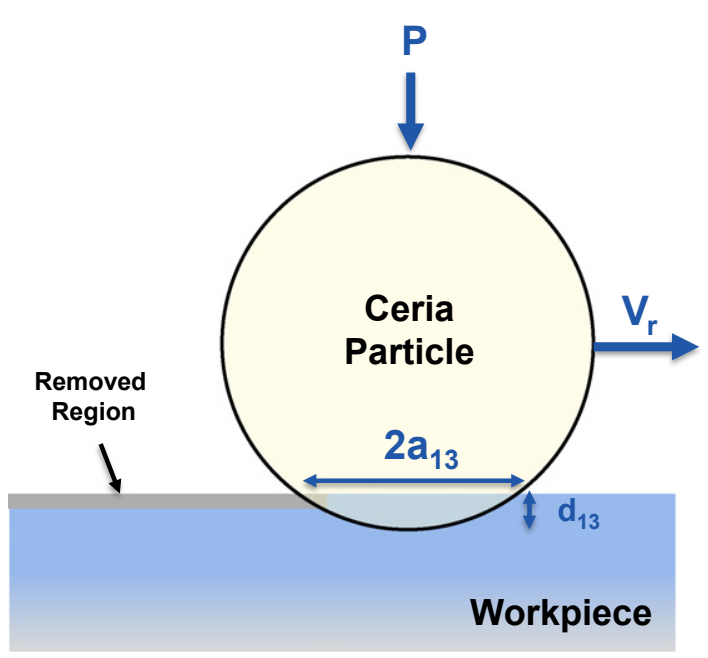

Side View

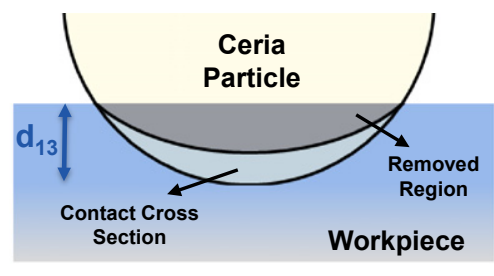

\section{Constant depth mechanism}

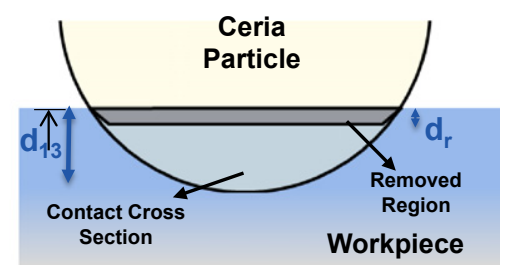

Front View

Fig. 10. Schematic illustration of two geometric material removal mechanisms of a sliding ceria particle (constant area fraction mechanism and constant depth mechanism).
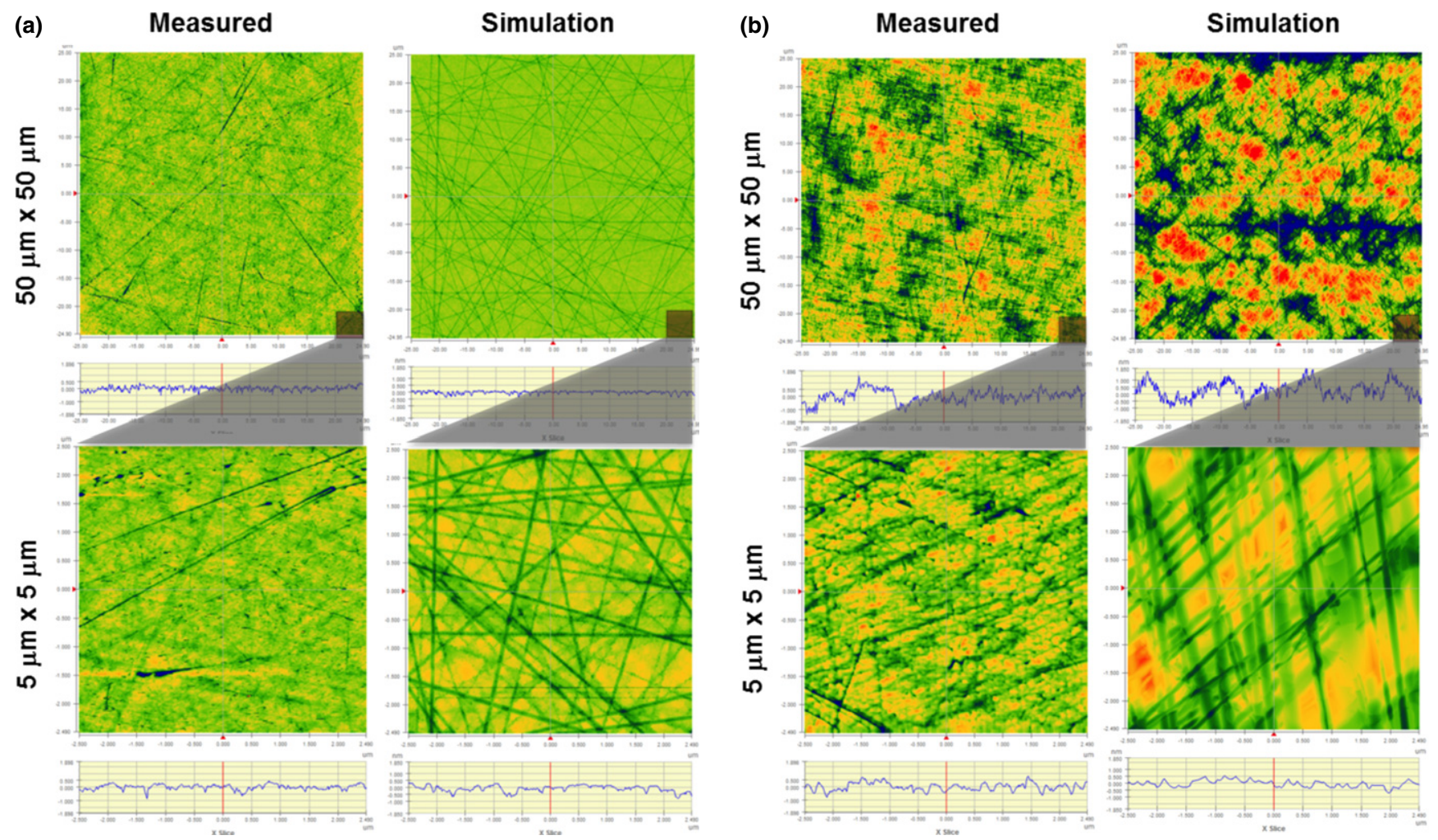

Fig. 11. Comparison of measured and simulated polished silica surfaces $(5 \mu \mathrm{m} \times 5 \mu \mathrm{m}$ and $50 \mu \mathrm{m} \times 50 \mu \mathrm{m})$ (a) using Stabilized Hastilite (S2) and (b) using Unstabilized Hastilite (S3).

the polishing particle independent of its size. Thus, adding up the removal by all particles gives a total removal proportional to the total load carried by all the particles which is consistent with the macroscopic Preston equation. The second type of material removal mechanism assumes a constant thickness of material $\left(d_{\mathrm{r}}\right)$ is removed independent of particle size (see Fig. 10 bottom right), referred to as the "constant depth" mechanism. In this case, the Preston equation does not automatically follow. However, as we will see below, at least for the types of PSD we have measured (sum of several exponentials), the Preston equation is still approximately satisfied.

\section{(4) Monte Carlo Polishing Simulations and Comparison with Experimental Data}

With an established formalism for determining the contact characteristics and the material removal function for each slurry particle, the next step of creating a simulated polished surface can now be performed. Using the Monte Carlo 
method, slurry particles were selected randomly from the PSD $[f(r)]$, and then randomly placed on a line location on the surface of an initially flat workpiece within a defined microscopic window. The linear density of particles is given by $N_{t}{ }^{1 / 2}$, where $N_{t}$ is the areal density of particles at the interface. Then, the particles made a trench (with the material removal function described above) along the surface all in the same, randomly selected direction (which determines the orientation of the line). The process was repeated with random directions until the roughness and power spectra of the surfaces are largely converged; typical simulations needed 300000 particles for the Stabilized Hastilite slurry (S2) and 30000 particles for Unstabilized Hastilite (S3) PSD using a $250 \times 250$ grid simulation window. The formation of a new track on a surface which already had roughness was treated by a scheme designed to reflect that a large particle cannot reach the bottom of a narrow trench, so material removal was reduced at that location.

The Monte Carlo simulated surfaces are shown in Fig. 11 using the Stabilized Hastilite (S2) and Unstabilized Hastilite (S3) slurries in two microscopic windows $(50 \mu \mathrm{m} \times 50 \mu \mathrm{m}$ and $5 \mu \mathrm{m} \times 5 \mu \mathrm{m}$ ) using the "constant depth" mechanism and using the parameters shown in Table II. These surfaces are compared side-by-side with the experimental data. Note the scales for each of the contour plots and lineouts in Fig. 11 are all the same for direct comparison. The simulations appear to capture the salient features (i.e., overall roughness magnitude, spatial scale length, surface texture, etc.) of the corresponding measured surfaces for both slurries. Figure 12 compares the power spectra of these same surfaces (both the simulation and measured) shown in Fig. 11. The calculated power spectra from the simulations again compare fairly well with the experimental data. Also, power spectra of both the simulation and experimental data show reasonable overlap between the two window sizes (i.e., spatial scales lengths), showing consistency of both the simulation and experiment over multiple spatial scale lengths.

Polishing simulations using the "constant depth" removal mechanism produced statistically very different surfaces than those produced by the "constant area fraction" removal mechanism. This is illustrated when comparing the slopes of the power spectra (see Fig. 13). Simulations carried out with the "constant depth" mechanism led to surfaces with much better statistical agreement with the experiment than those carried out with the "constant area fraction" mechanism, which had too high a slope in the power spectra (on log-log plot). Interestingly, the form of power spectra dependence (i.e., its slope) is principally correlated with the material removal mechanism and almost independent of the other input parameters in the simulation.

All the input parameters used in the polishing simulations (listed in Table II) were either measured or literature values, except for: (1) the chemical removal depth $\left(d_{\mathrm{m}}=0.4 \AA\right)$, and (2) number density of particles present at the interface $\left(N_{\mathrm{t}}=30 \mu \mathrm{m}^{2}\right)$. These parameters were adjusted to best match the experimental data. Note, however, the same values of these two parameters were used in all the simulations for the various slurries and window sizes. Also, the determined values for these two parameters did give reasonable physical values. A single bond length of $\mathrm{Si}-\mathrm{O}-\mathrm{Si}$ is $1.6 \AA$ A, hence, a $d_{\mathrm{m}}$ value of $0.4 \AA$ suggests $\sim 1 / 4$ of $\mathrm{Si}-\mathrm{O}-\mathrm{Si}$ molecules are removed in a single pass of a ceria particle. Also, the theoretical single layer stacking of particles at the interface for the mean particle size is $\sim 100 \mu^{2}$; getting a best fit value of $N_{\mathrm{t}}=30 \mu \mathrm{m}^{-2}$ suggests a fill fraction of particles of $\sim 1 / 3$, which is reasonable.

(5) Comparison with Macroscopic Material Removal Rate (Preston Equation)

To test the validity of the EHG model's and the polishing simulations' consistency to the observed macroscopic behav-
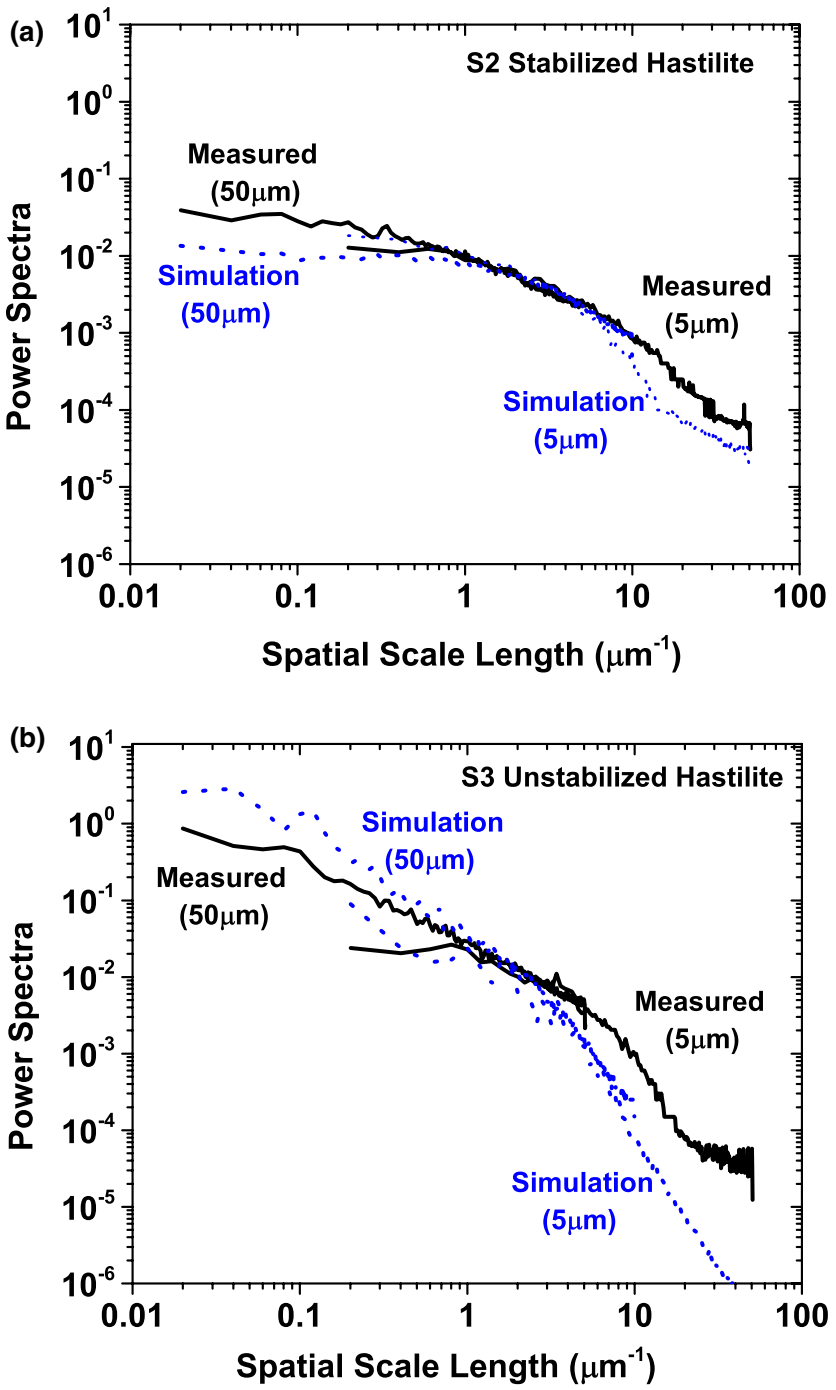

Fig. 12. Comparison of measured and simulated power spectra of the polished fused silica surfaces for (a) stabilized hastilite (S2) and (b) unstabilized hastilite (S3).



Fig. 13. Measured versus calculated power spectra of the polished fused silica surface for stabilized hastilite (S2) using two different removal mechanisms [constant area fraction (dash-dot lines) and constant depth (CD) (dotted lines)].

ior, the macroscopic material removal rate or Preston equation [Eq. (1)] can be estimated using average microscopic material removal parameters as follows: 


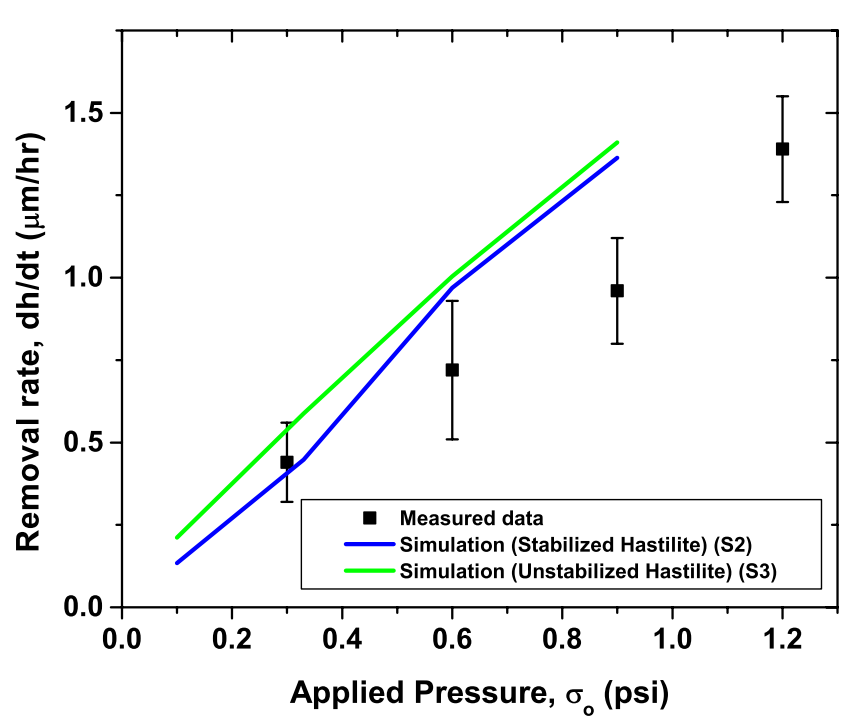

Fig. 14. (a) Measured and calculated global material removal rate using Ensemble Hertzian Gap model for two slurries [Unstabilized Hastilite (S2) and Stabilized Hastilite (S3)] as a function of applied pressure.

$$
\frac{\mathrm{d} h}{\mathrm{~d} t} \approx N_{t} f_{\mathrm{a}} f_{\mathrm{r}} V_{\mathrm{r}}\left(f_{\mathrm{p}} d_{\mathrm{p}} 2 a_{\mathrm{p}}+f_{\mathrm{m}} d_{\mathrm{m}} 2 a_{\mathrm{m}}\right)
$$

where $f_{\mathrm{r}}$ is the fraction of active particles in the PSD, $f_{\mathrm{p}}$ is the fraction of active particles that have a load/particle greater than $P_{\text {crit }}, 2 a_{\mathrm{p}}$ is the average contact zone diameter for particles that have a load/particle greater than $P_{\text {crit }}, f_{\mathrm{m}}$ is the fraction of active particles that have load/particle less than $P_{\text {crit }}$, and $a_{\mathrm{m}}$ is the average contact zone radius for active particles that have load/particle less than $P_{\text {crit }}$.

Using the measured and calculated values listed in Tables I and II and evaluating Eq. (9) gives a removal rate of $0.54 \mu \mathrm{m} / \mathrm{h}$ for the Stabilized Hastilite slurry (S2) and $0.77 \mu \mathrm{m} / \mathrm{h}$ for the Unstabilized Hastilite slurry (S3). The experimentally measured material removal rate is $0.5 \pm 0.1 \mu \mathrm{m} / \mathrm{h}$. This similarity in the calculated and measured global material rate is fairly striking as the calculated value comes from only the measured and calculated parameters in the model such as PSD, fraction of pad area making contact, load/particle and contact zones from the EHG model, and the plastic and chemical removal functions. Note that the values would be very different if only the chemical or only the plastic removal mechanism was implemented in the model, and consistency with the measured data would not be obtained.

Another test is to determine whether the model predicts a similar load dependence on the macroscopic material removal rate. Figure 14 compares the measured average thickness removal rate with the calculated removal using the EHG model and Eq. (9) for different applied loads. Both the measured and calculated data show a nominal linear dependence. The general behavior is an increase in $f_{\mathrm{r}}$ with applied load leading to more particles removing material, but a decrease in $f_{\mathrm{p}}$ with applied load leading to less average removal per particle (i.e., more particle removing via the chemical mechanism). The calculated linear increase in material removal rate with applied load is consistent with the experimentally determined macroscopic load dependence on material removal rate and with the Preston Equation (Eq. (1)).

\section{Conclusions}

For the first time, to the authors' knowledge, measured polished surfaces have been correlated with simulated surfaces over multiple scale lengths describing texture, roughness, and power spectra. The results of the experiments and simulations imply a number of key insights regarding optical polishing: (1) the size dependence of the tail end of the PSD of the slurry strongly influences the roughness of the polished surface; (2) only a small contact area between the workpiece and pad occurs at any given time; (3) material removal with ceria particles likely occurs both by chemical and plastic mechanisms removing either $0.4 \AA$ per pass or $1 \mathrm{~nm}$ per pass, respectively; (4) the transition from chemical to plastic removal occurs at a critical load per particle $\left(P>P_{\text {crit }} \approx 5 \times 10^{-5} \mathrm{~N}\right)$; and (5) the single particle removal depth does not depend on particle size, however, the particle contact length increases with particle size (i.e., the removal function is the constant depth mechanism). This study represents an important step toward a greater understanding of the complex microscopic interactions that occur during polishing and has applied implications for developing new, cost effective polishing processes to control the resulting workpiece roughness.

\section{Acknowledgment}

This work performed under the auspices of the U.S. Department of Energy by Lawrence Livermore National Laboratory under contract DE-AC5207NA27344 within the LDRD program.

\section{References}

${ }^{1}$ N. J. Brown, "A Short Course in Optical Fabrication Technology", Optical Society of America Annual Meeting, LLNL Preprint, UCRL-86796. (1981).

${ }^{2}$ F. Preston, "The Structure of Abraded Glass Surfaces," Trans. Opt. Soc., 23 [3] 141-6 (1922).

${ }^{3}$ E. Terrell and C. Higgs, "Hydrodynamics of Slurry Flow in Chemical Mechanical Polishing," J. Electrochem. Soc., 153 [6] K15-22 (2006).

${ }^{4}$ S. Runnels and L. Eyman, "Tribology Analysis of Chemical Mechanical Polishing," J. Electrochem. Soc., 141 [6] 1698-701 (1994).

${ }^{5}$ S. Park, C. Cho, and Y. Ahn, "Hydrodynamic Analysis of Chemical Mechanical Polishing Process," J. Tribology Int., 33, 723-30 (2000).

${ }^{6}$ T. Suratwala, M. Feit, and R. Steele, "Material Removal and Surface Figure During pad Polishing of Fused Silica," J. Am. Ceram. Soc., 93 [5] 1326-40 (2010).

${ }^{7}$ T. Suratwala, R. Steele, M. Feit, R. Desjardin, and D. Mason, "Convergent Pad Polishing of Amorphous Fused Silica," Int. J. Appl. Glass Sci., 3 [1] 14-28 (2012).

${ }^{8}$ M. Feit, R. Desjardin, W. Steele, and T. Suratwala, "Optimized Pitch Button Blocking for Polishing High-Aspect-Ratio Optics," Appl. Opt. 51 [35] 8350-9(2012).

${ }^{9}$ J. Luo and D. Dornfeld, "Effects of Abrasive Size Distribution in Chemical Mechanical Planarization: Modeling and Verification" IEEE T. Semicond. M. 16 (3) 469-76 (2003).

${ }^{10}$ J. Luo and D. Dornfeld, "Material Removal Mechanism in Chemical Mechanical Polishing: Theory and Modeling," IEEE T. Semiconduct. M, 14, 112-33 (2001).

${ }^{11}$ M. Bastaninejad and G. Ahmadi, "Modeling the Effects of Abrasive Size Distribution, Adhesion, and Surface Plastic Deformation on Chemical Mechanical Polishing”, J. Electrochem. Soc. 152 (9) G720-30 (2005).

${ }^{12}$ Y. Sampurno, F. Sudargho, Y. Zhuang, T. Ashizawa, H. Morishima, and A. Philipossian, "Effect of Cerium Oxide Particles Sizes in Oxide Chemical Mechanical Planarization," Electrochem. Solid State, 12 [6] H191-H194 (2009).

${ }^{13}$ C. Wang, P. Sherman, A. Chandra, and D. Dornfeld, "Pad Surface Roughness and Slurry Particle Size Distribution Effects on Material Removal Rate in Chemical Mechanical Planarization," CIRP Ann., 54 [1] 309-12 (2005).

${ }^{14}$ T. Suratwala, R. Steele, M. D. Feit, L. Wong, P. Miller, J. Menapace, P. Davis, "Effect of Rogue Particles on the Sub-Surface Damage of Fused Silica During Grinding/Polishing," J. Non-Cryst. Solids, 354 [18] 2023-37 (2008).

${ }^{15}$ G. Basim, J. J. Adler, U. Mahajan, R. K. Singh, and B. M. Moudgil, "Effect of Particle Size of Chemical Mechanical Polishing Slurries for Enhanced Polishing with Minimal Defects," J. Electrochem. Soc., 147 [9] 3523-8 (2000).

${ }^{16}$ E. Remsen, S. Anjur, D. Boldridge, M. Kamiti, S. Li, T. Johns, C. Dowell, J. Kasthurirangan, and P. Feeney, "Analysis of Large Particle Count in Fumed Silica Slurries and its Correlation with Scratch Defects Generated by CMP," J. Electrochem. Soc., 153 [5] G453-61 (2006).

${ }^{17}$ H. Kim, J. Yang, M. Kim, D. Oh, C. Lee, S. Kim, and T. Kim, "Effects of Ceria Abrasive Particle Size Distribution Below Wafer Surface on In-Wafer Uniformity During Chemical Mechanical Processing," J. Electrochem. Soc., 158 [6] H536-640 (2011).

${ }^{18}$ T. Eusner, N. Saka, J.-H. Chun, S. Armini, M. Moinpour, and P. Fischer, "Controlling Scratching in $\mathrm{Cu}$ Chemical Mechanical Planarization," J. Electrochem. Soc., 156 [7] H528-34 (2009). 
${ }^{19}$ R. Dylla-Spears, M. Feit, P. Miller, W. Steele, T. Suratwala, and L. Wong, "Method for Preventing Agglomeration of Charged Colloids Without Loss of Surface Activity"; US Provisional Patent Application (IL-12647) October, 2012

${ }^{20}$ A. Shorey, K. Kwong, K. Johnson, and S. Jacobs, "Nanoindentation Hardness of Particles Used in Magnetorheological Finishing (MRF)," Appl. Optics, 9 [28] 5194-204 (2009).

${ }^{21}$ M. J. Cumbo, D. Fairhurst, S. D. Jacobs, and B. E. Puchebner, "Slurry Particle Size Evolution During the Polishing of Optical Glass," Appl. Optics, 34 [19] 3743-55 (1995)

${ }^{22} \mathrm{~K}$. Johnson, Contact Mechanics,92-3. Cambridge University Press, Cambridge, UK, 1985.
${ }^{23}$ B. Lawn, Fracture of Brittle Solids, 2nd edition. Cambridge University Press, Cambridge, UK, 1993.

${ }^{24}$ T. Suratwala, L. Wong, P. Miller, M. Feit, J. Menapace, R. Steele, P. Davis, and D. Walmer, "Sub-Surface Mechanical Damage Distributions During Grinding of Fused Silica," J. Non-Cryst. Solids, 352, 5601-17 (2006).

${ }^{25}$ L. Cook, "Chemical Processes in Glass Polishing," J. Non-Cryst. Solids, 120, 152-71 (1990).

${ }^{26}$ P. Partridge, A. Fookes, E. Nicholson, T. Pearce, and G. Meaden, "Nanoscale Ductile Grinding of Glass by Diamond Fibres," J. Mater. Sci., 31, 5051-7 (1996).

${ }^{27}$ N. Ong and V. Venkatesh, "Semi-Ductile Grinding and Polishing of Pyrex Glass," J. Mater. Process. Tech., 83, 261-6 (1998). 